\title{
Fabrication and physicochemical characterization of porous composite microgranules with selenium oxyanions and risedronate sodium for potential applications in bone tumors
}

\author{
This article was published in the following Dove Press journal: \\ International Journal of Nanomedicine \\ 7 August 2017 \\ Number of times this article has been viewed
}

\author{
Joanna Kolmas' \\ Kamil Pajor' \\ Lukasz Pajchel' \\ Agata Przekora ${ }^{2}$ \\ Grażyna Ginalska² \\ Ewa Oledzka ${ }^{3}$ \\ Marcin Sobczak ${ }^{3}$ \\ 'Department of Inorganic and \\ Analytical Chemistry, Faculty of \\ Pharmacy with Laboratory Medicine \\ Division, Medical University of \\ Warsaw, Warsaw, ${ }^{2}$ Department of \\ Biochemistry and Biotechnology, \\ Faculty of Pharmacy with Medical \\ Analytics Division, Medical University \\ of Lublin, Lublin, ${ }^{3}$ Department of \\ Biomaterials Chemistry, Faculty of \\ Pharmacy with Laboratory Medicine \\ Division, Medical University of \\ Warsaw, Warsaw, Poland
}

\begin{abstract}
Nanocrystalline hydroxyapatite containing selenite ions (SeHA; 9.6 wt.\% of selenium) was synthesized using wet method and subject to careful physicochemical analysis by powder X-ray diffraction, Fourier transform infrared spectroscopy, transmission electron microscopy, solid-state nuclear magnetic resonance, wavelength dispersive X-ray fluorescence, and inductively coupled plasma optical emission spectrometry. SeHA was then used to develop the seleniumcontaining hydroxyapatite/alginate (SeHA/ALG) composite granules. Risedronate sodium (RIS) was introduced to the obtained spherical microgranules of a size of about $1.1-1.5 \mathrm{~mm}$ in 2 ways: during the granules' preparation (RIS solution added to a suspension of ALG and SeHA), and as a result of SeHA/ALG granules soaking in aqueous RIS solution. The analysis made using ${ }^{13} \mathrm{C}$ and ${ }^{31} \mathrm{P}$ cross-polarization magic angle spinning nuclear magnetic resonance confirmed the presence of RIS and its interaction with calcium ions. Then, the release of selenium (inductively coupled plasma optical emission spectrometry) and RIS (high-performance liquid chromatography) from microgranules was examined. Moreover, cytotoxicity of fabricated granules was assessed by MTT test. Selenium release was biphasic: the first stage was short and ascribed to a "burst release" probably from a hydrated surface layer of SeHA crystals, while the next stage was significantly longer and ascribed to a sustained release of selenium from the crystals' interior. The study showed that the method of obtaining microgranules containing RIS significantly affects its release profile. Performed cytotoxicity test revealed that fabricated granules had high antitumor activity against osteosarcoma cells. However, because of the "burst release" of selenium during the first $10 \mathrm{~h}$, the granules significantly reduced viability of normal osteoblasts as well.
\end{abstract}

Keywords: composites, nanocrystalline hydroxyapatite, drug release, cytotoxicity, antitumor activity, ionic substitutions, biomaterials, bisphosphonates

\section{Introduction}

Bone tissue defects are one of the most challenging problems in clinical orthopedics and surgical dentistry. Infections, trauma, bone tumors and congenital osseous diseases may all cause significant bone defects. ${ }^{1}$ Ranging from small lacks in flat bone to large voids in long bone, they all require specific techniques of reconstruction. In many cases, the "gold standard" in terms of osteointegration is obtained using autologous bone graft. ${ }^{2}$ However, a limited supply of this type of bone graft and the risk of chronic pain or infection at the explant site reduce its use. Allografts and xenografts may eliminate these limitations, but problems with immune reactions, rejections and slower osteointegration can occur. ${ }^{3,4}$
Correspondence: Joanna Kolmas Department of Inorganic and Analytical Chemistry, Faculty of Pharmacy with Laboratory Medicine Division, Medical University of Warsaw, ul Banacha I, 02-097 Warsaw, Poland

Tel +48225720755

Fax +48225720784

Email joanna.kolmas@wum.edu.pl (c)
hereby accept the Terms. Non-commercial uses of the work are permitted without any further permission from Dove Medical Press Limited, provided the work is properly attributed. For permission for commercial use of this work, please see paragraphs 4.2 and 5 of our Terms (https://www.dovepress.com/terms.php). 
Nowadays, attention has been focused on the use of synthetic biomaterials holding the ability to replace defective bone tissue. ${ }^{5}$ Synthetic bone substitutes based on calcium phosphate materials ( $\mathrm{CaPs}$ ) in various forms (ie, granules, cements, pastes, geometric blocks) are commonly used in bone reconstruction. Among CaPs used as biomaterials, hydroxyapatite $\left(\mathrm{HA} ; \mathrm{Ca}_{10}\left(\mathrm{PO}_{4}\right)_{6}(\mathrm{OH})_{2}\right)$ is the most popular in biomaterials engineering, due to its similarity to the mineral component of nature bone and dental mineralized tissues. ${ }^{6,7}$ Moreover, it was reported that HA could be substituted by various ions that have an impact on bone metabolism, bone formation or bone disease therapy. ${ }^{8}$ Unfortunately, low mechanical strength significantly limits the use of HA. Therefore, recently HA materials have been used as polymer/ ceramic composite components, which can not only fulfill osseous tissue defects but also deliver drugs directly to the bone tissue. ${ }^{910}$ Polymeric components improve mechanical properties and allow the controlled release of a drug.

The aim of the present work was the preparation and physicochemical and biological characterization of microgranules containing selenium-substituted nanocrystalline HA, alginate sodium and risedronate sodium (RIS).

Selenium is a trace element of human tissues, playing an important role as a component of antioxidant enzymes and selenoproteins. ${ }^{11}$ Its deficiency may produce serious diseases, that is, Keshan disease (cardiomyopathy in children) or severe chondrodystrophy. ${ }^{12}$ It has been reported that selenium has a great impact on bone density and metabolism. ${ }^{13}$ Additionally, numerous studies have declared its chemopreventive and therapeutic activity against various types of cancers. ${ }^{14-17}$

ALG is a natural ionic polymer with L-guluronate and D-mannuronate as major components. It is typically extracted from brown algae (Phaeophyceae) ${ }^{18,19}$ This polysaccharide is biodegradable and biocompatible and due to cross-linking properties, able to form gels, beads, fibers and foams. ALGs have been combined with various bioceramics to form promising scaffolds for tissue regeneration and drugdelivery systems. ${ }^{20,21}$

RIS belongs to the bisphosphonates (BPs) group. BPs are commonly used as antiresorptive agents for the treatment of osteoporosis, Paget's disease or bone tumors and bone metastasis. ${ }^{22,23}$ RIS has potency to inhibit osteoclast-mediated bone resorption. Moreover, RIS acts as an inhibiting factor for tumor cells' adhesion and proliferation. However, doses of RIS for their antitumor effect should be high. It should be also noted that the absorption of RIS after standard, oral administration and its bioavailability are very low, thus problems with significant side effects and insufficient efficacy may occur. ${ }^{24,25}$
In our work, we synthesized nanocrystalline HA enriched in selenium-containing hydroxyapatite (SeHA) and we prepared and characterized microgranules composed of ALG and SeHA (selenium-containing hydroxyapatite/alginate [SeHA/ALG]). In the next step, we produced SeHA/ALG microgranules containing RIS by 2 different routes. Together with their chemopreventive and anticancer activity, these composites were designed to support the bone regeneration. The physicochemical properties of the obtained SeHA powder and microgranules were investigated in detail by several analytical methods: powder X-ray diffractometry (PXRD), Fourier transform infrared spectroscopy (FT-IR), solid-state nuclear magnetic resonance (ssNMR), transmission and scanning electron microscopy (TEM and SEM) and wavelength dispersive X-ray fluorescence (WD-XRF). Moreover, the release profiles of selenium and RIS from the composite granules were examined by inductively coupled plasma optical emission spectrometry (ICP-OES) and highperformance liquid chromatography (HPLC), respectively. To evaluate potential antitumor activity of produced granules, preliminary biological test using osteosarcoma-derived cell line was performed in in vitro conditions.

\section{Materials and methods Materials}

All the reagents for the synthesis of SeHA, alginate sodium and diammonium carbonate $\left(\left[\mathrm{NH}_{4}\right]_{2} \mathrm{CO}_{3}\right)$ were purchased from Sigma-Aldrich Inc. (St Louis, MO, USA). RIS of USP Reference Standard grade was obtained from USP (Rockville, MD, USA). Calcium chloride, potassium chloride and acetonitrile of HPLC grade were purchased from Avantor Performance Materials (Gliwice, Poland). Tetrabutylammonium hydroxide solution $40.0 \%$ (v/v) in water, sodium pyrophosphate and glacial acetic acid, reagents all of analytical grade, were purchased from Sigma-Aldrich Inc. Water was deionized and further purified by means of a Milli-Q Water Purification System (Millipore, Molsheim, France). The standard solutions of selenium $1,000 \mu \mathrm{g} / \mathrm{mL}$ were purchased from J.T. Baker (Deventer, Holland).

\section{Materials for cell culture experiment}

Human osteoblast-like cell line derived from osteosarcoma (Saos-2), normal human fetal osteoblasts (hFOB 1.19) and McCoy's 5A culture medium were purchased from ATCCLGC Standards (Teddington, UK). Fetal bovine serum (FBS) was obtained from Pan-Biotech (Aidenbach, Germany). $25 \mathrm{~cm}^{2}$ T-flasks, 96-multiwell plates, PBS, DMEM/Ham F12 medium, G418, penicillin-streptomycin solution, MTT, 
and dodecyl sulfate sodium salt (SDS) were purchased from Sigma-Aldrich Chemicals (Lublin, Poland). Hydrochloric acid was supplied by Avantor Performance Materials.

\section{Preparation of SeHA}

For the preparation of SeHA for this study, we used the wet method previously described. ${ }^{26}$ Briefly, $50 \mathrm{~mL}$ of $0.5 \mathrm{M}\left(\mathrm{NH}_{4}\right)_{2} \mathrm{HPO}_{4}$ solution was added to $50 \mathrm{~mL}$ of $0.08 \mathrm{M}$ $\mathrm{Na}_{2} \mathrm{SeO}_{3} \cdot 5 \mathrm{H}_{2} \mathrm{O}$ and dropwise added to $400 \mathrm{~mL}$ of $0.1 \mathrm{M}$ $\mathrm{Ca}\left(\mathrm{NO}_{3}\right)_{2} \cdot 4 \mathrm{H}_{2} \mathrm{O}$ solution. Throughout the reaction, the $\mathrm{pH}$ was stabilized at 9.5 using ammonium hydroxide solution. The temperature was controlled at $70^{\circ} \mathrm{C}$. The mixture was allowed to age for further $24 \mathrm{~h}$ at room temperature. The suspension was then filtered and washed several times with distilled water and dried overnight at $130^{\circ} \mathrm{C}$. For comparison, pure unsubstituted HA was synthesized via the same route.

\section{Granules' preparation}

SeHA and HA powders were used to prepare porous apatite/ alginate granules (SeHA/ALG) and (HA/ALG), respectively. First, a viscous $5 \%$ aqueous solution of ALG was obtained by intensive stirring at $40^{\circ} \mathrm{C}$. Then $2 \mathrm{~g}$ of fine powder of SeHA (HA) and $0.5 \mathrm{~g}$ of $\mathrm{NH}_{4} \mathrm{HCO}_{3}$ were added to $20 \mathrm{~mL}$ of ALG solution. The obtained slurry was mixed carefully and then squeezed by a syringe needle into the $1.5 \% \mathrm{CaCl}_{2}$ solution. The small spherical drops were produced due to the crosslinking between $\mathrm{Ca}^{2+}$ cations and the carboxylate anions of glucuronate units in ALG. The obtained granules were washed several times with water and dried at $40^{\circ} \mathrm{C}$ for $48 \mathrm{~h}$.

\section{Preparation of RIS-loaded granules (SeHA/ALG/RIS)}

First route (SeHA/ALG/RIS I)

During the preparation of porous granules, RIS was added $(50 \mathrm{mg}$ ) to $5 \%$ ALG solution. Then the SeHA powder and $\mathrm{NH}_{4} \mathrm{HCO}_{3}$ were added to obtain dense slurry (identical to that in the granules' preparation). The slurry was used to produce the small porous granules that were washed with distilled water and dried at $40^{\circ} \mathrm{C}$ for $48 \mathrm{~h}$.

\section{Second route (SeHA/ALG/RIS II)}

RIS was dissolved in $1 \mathrm{mmol} / \mathrm{L} \mathrm{KCl}$ solution at a concentration of $0.01 \mathrm{mmol}$ per $1 \mathrm{~mL}$. Then the granules were soaked for $2 \mathrm{~h}$ in the above RIS solution in amounts of 1 granule per $1 \mathrm{~mL}$. The granules were washed gently with $\mathrm{KCl}$ solution and dried at $40^{\circ} \mathrm{C}$ for $48 \mathrm{~h}$.

\section{Release of selenium and RIS sodium from the microgranules}

For dissolution of selenium from selenium-containing granules, $3 \mathrm{~g}$ of granules were added to a round-bottomed flask, using $100 \mathrm{~mL}$ of buffer $\mathrm{pH}=7.4$ at $37^{\circ} \mathrm{C} \pm 0.5^{\circ} \mathrm{C}$ as the dissolution medium. Samples aliquots of $10 \mathrm{~mL}$ were taken at $0.5,1,2,4,6,24,48,72,96,120,144,168$ and $192 \mathrm{~h}$ and filtered through $0.22 \mu \mathrm{m}$ nylon filters into the glass flask. Every time a sample was taken, $10 \mathrm{~mL}$ of buffer was added to the round-bottomed flask.

For the dissolution of RIS from RIS-loaded granules, $15 \mathrm{mg}$ of granules were added to the round-bottomed flask, using $5 \mathrm{~mL}$ of buffer $\mathrm{pH}=7.4$ at $37^{\circ} \mathrm{C} \pm 0.5^{\circ} \mathrm{C}$ as the dissolution medium. Samples aliquots of $1 \mathrm{~mL}$ were taken at 1,5 , $10,20,30,45,60,90,120,150,180,210,240$ and $300 \mathrm{~min}$ and filtered through $0.22 \mu \mathrm{m}$ nylon filters into the glass flask. Every time a sample was taken, $1 \mathrm{~mL}$ of buffer was added to the round-bottomed flask.

\section{Analytical methods}

PXRD analysis of HA powders was performed using a Bruker D8 Discover diffractometer (a step size $0.024^{\circ}$ and a $2 \Theta$ range from 20 to $70^{\circ}$; Bruker, Poznań, Poland). For estimation of crystallite size, we calculated the values of full width at half maximum of the reflection of the (002) and (300) planes, representing the crystallites along the $c$-axis and $a$-axis, respectively. The Scherrer formula was used. ${ }^{27}$

The crystals' morphology was determined using High Performance Transmission electron microscope JEM 1400 (JEOL Co., Tokyo, Japan) equipped with 11 Megapixel TEM Camera MORADA G2 (EMSIS GmbH, Münster, Germany).

The chemical composition of apatitic powders $(\mathrm{Ca}, \mathrm{P}$ and Selenium content) was determined by using WD-XRF (Advant'XP; Thermo-ARL; ARL, Lausanne, Switzerland).

FT-IR measurements were carried out using a Spectrum 1000 spectrometer working at mid-infrared range (Spectrum 1000; Perkin Elmer, Warsaw, Poland). The obtained samples (apatitic powders and composite granules) were mixed with $\mathrm{KBr}$ in weight ratio 1:100 and pressed into pellets.

The magic angle spinning nuclear magnetic resonance (MAS NMR) spectra of ${ }^{31} \mathrm{P}$ and ${ }^{13} \mathrm{C}$ nuclei were recorded using a Bruker Avance $400 \mathrm{WB}$ spectrometer. For ${ }^{31} \mathrm{P}$ and ${ }^{13} \mathrm{C}$ MAS NMR experiments, the samples were spun at 7 and $7.5 \mathrm{kHz}$, respectively. In all the experiments, the crosspolarization technique was used. ${ }^{31} \mathrm{P}$ spectra were taken at a resonance frequency at $160 \mathrm{MHz}$ with a10 s delay time, $2 \mathrm{~ms}$ contact time and a $\pi / 2$ pulse of $2.7 \mu \mathrm{s}$. The ${ }^{13} \mathrm{C} \mathrm{CP}$ MAS NMR spectra were recorded with a $15 \mathrm{~s}$ delay time, $2 \mathrm{~ms}$ 
contact time and a $\pi / 2$ pulse of $2.4 \mu$ s. The chemical shifts were referenced to tetramethylsilane and $85 \% \mathrm{H}_{3} \mathrm{PO}_{4}$, for ${ }^{13} \mathrm{C}$ and ${ }^{31} \mathrm{P}$ NMR, respectively.

RIS in degradation solutions was determined by HPLC using the chromatographic equipment consisting of a Varian Prostar 210 isocratic pump (Palo Alto, CA, USA) and a Rheodyne 7725i injector (Cotati, CA, USA) with a $50 \mathrm{~mL}$ sample loop. Detection was performed by a Varian Prostar 325 ultraviolet detector, using a detection wavelength of $262 \mathrm{~nm}$.

Chromatographic conditions and the measurement procedure were previously described. ${ }^{28}$ The LC column used was a $4.6 \mathrm{~mm}$ i.d. $\times 250 \mathrm{~mm}$ length XTerra RP 18 analytical column that was purchased from Whaters (Milford, Ireland). The mobile phase consisted of 0.01 M tetrabutylammonium hydroxide and $0.005 \mathrm{M}$ sodium pyrophosphate $(\mathrm{pH} 7.0)$ mixed with acetonitrile in a ratio $(78: 22, \mathrm{v} / \mathrm{v})$. It was degassed by sonication prior to use.

The flow rate of the mobile phase was maintained at $1 \mathrm{~mL} / \mathrm{min}$. HPLC analysis was conducted at ambient temperature. Peak areas were measured for the quantitation of the RIS. Stock standard solutions of RIS $100.00 \mu \mathrm{g} / \mathrm{mL}$ were prepared by dissolving the appropriate amount in water. Calibration standards were prepared over the concentration range of $0.50,1.00,10.00,20.00,30.00,40.00,60.00$ and $80.00 \mu \mathrm{g} / \mathrm{mL}$ for RIS by appropriate dilutions of the abovementioned stock standard solution in $10.0 \mathrm{~mL}$ of buffer. Calibration standards were analyzed in triplicate for the calibration curve.

Selenium in degradation solutions was determined by ICPOES using an Optima 3100XL spectrometer (Perkin Elmer).

Selenium calibration standards were prepared over the concentration range of 1.00, 10.00, 20.00, 50.00, 150.00 and $300.00 \mu \mathrm{g} / \mathrm{mL}$ for selenium by appropriate dilutions of the stock standard solutions of selenium $1,000 \mu \mathrm{g} / \mathrm{mL}$ in $10.0 \mathrm{~mL}$ of buffer. Calibration standards were analyzed in triplicate for the calibration curve.

\section{Cell culture experiment}

Human tumor cells derived from osteosarcoma (Saos-2) were cultured in McCoy's 5A medium supplemented with 15\% FBS and antibiotics: $100 \mathrm{U} / \mathrm{mL}$ penicillin, $100 \mu \mathrm{g} / \mathrm{mL}$ streptomycin. hFOB 1.19 were cultured in a 1:1 mixture of DMEM/Ham F12 medium without phenol red supplemented with $10 \%$ FBS and antibiotics: $300 \mu \mathrm{g} / \mathrm{mL} \mathrm{G418,} 100 \mathrm{U} / \mathrm{mL}$ penicillin, $100 \mu \mathrm{g} / \mathrm{mL}$ streptomycin. Saos-2 cells were maintained at $37^{\circ} \mathrm{C}$ and $\mathrm{hFOB} 1.19$ cells at $34^{\circ} \mathrm{C}$ (ATCC recommendations) in a humidified atmosphere of $5 \% \mathrm{CO}_{2}$ and $95 \%$ air. Cytotoxicity of prepared granules against tumor and normal osteoblasts was assessed indirectly using extracts of the granules. Both, extraction procedure and cytotoxicity test were performed in accordance with international standards ISO 10993-5. ${ }^{29}$ Extracts were prepared via incubation of granules in a complete culture medium for $24 \mathrm{~h}$ at $37^{\circ} \mathrm{C}$. Before the extraction, highly absorbent granules were completely soaked in the medium, then $1 \mathrm{~mL}$ of culture medium was added per every $100 \mathrm{mg}$ of granules (weight in a dry state was considered). Upon $24 \mathrm{~h}$ extraction, the samples were centrifuged and supernatants (extracts) were collected. Culture media incubated without the granules for $24 \mathrm{~h}$ at $37^{\circ} \mathrm{C}$ served as a negative control of cytotoxicity (100\% viability). $100 \%$ and $50 \%$ (diluted using medium) extracts of the granules were tested.

The cells were seeded in 96-multiwell plates in $100 \mu \mathrm{L}$ of appropriate culture medium at a concentration of $3 \times 10^{5}$ Saos- 2 cells $/ \mathrm{mL}\left(3 \times 10^{4}\right.$ cells perwell $)$ and $1.5 \times 10^{5} \mathrm{hFOB}$ 1.19 cells $/ \mathrm{mL}\left(1.5 \times 10^{4}\right.$ cells per well). Upon $24 \mathrm{~h}$ incubation at $37^{\circ} \mathrm{C}$, when tumor and normal cells reached $90 \%$ confluence, the culture media were replaced with $100 \mu \mathrm{L}$ of granule extracts. After $24 \mathrm{~h}$ exposure to the extracts, viability of cells was determined using MTT test. Briefly, $25 \mu \mathrm{L}$ of $5 \mathrm{mg} / \mathrm{mL}$ MTT solution in PBS was added to each well, plates were incubated for $3 \mathrm{~h}$ at $37^{\circ} \mathrm{C}$, and then formazan crystals formed in viable cells were dissolved using 10\% SDS solution prepared in $0.01 \mathrm{M} \mathrm{HCl}$. Absorbance (Abs) of resultant solution was measured at $570 \mathrm{~nm}$ using Bio Tek Synergy H4 Hybrid Microplate Reader (Swindon, UK). The test was carried out in 3 independent experiments $(n=3)$ and performed in quadruplicate. The cell viability was determined based on the obtained Abs values using the following formula:

$$
\text { Viability }[\%]=\frac{\text { Abs of the sample }}{\text { Abs of negative control }} \times 100
$$

Results, obtained with MTT test, were analyzed using GraphPad Prism 5, Version 5.03 Software (GraphPad Software, Inc., La Jolla, CA, USA). The unpaired $t$-test was applied to assess whether reduction in cell viability compared with the negative control (100\% viability) was statistically significant $(P<0.05)$.

\section{Results and discussion Selenium-containing HA}

During the synthesis, the amount of reagents was calculated by assuming the mechanism of substitution proposed in our previous work. ${ }^{26}$

$$
\begin{aligned}
\mathrm{Ca}_{10}\left(\mathrm{PO}_{4}\right)_{6}(\mathrm{OH})_{2}+\mathrm{SeO}_{3}{ }^{2-} \rightarrow & \mathrm{Ca}_{10-\mathrm{x}}\left(\mathrm{PO}_{4}\right)_{6-\mathrm{x}}\left(\mathrm{SeO}_{3}\right)_{\mathrm{x}}(\mathrm{OH})_{2-\mathrm{x}} \\
& +\mathrm{xCa}^{2+}+\mathrm{xPO}_{4}{ }^{3-}+\mathrm{xOH}^{-}
\end{aligned}
$$


To maintain a charge balance, substitution of trivalent phosphate anion with divalent selenite anion should be compensated by simultaneous release of calcium cation and hydroxyl anion. In this work, we have chosen a high concentration of selenium ( $x=1.2 ; 9.70 \mathrm{wt} . \%)$. The selenium content, determined by WD-XRF, was slightly lower than assumed (9.60 wt.\%).

PXRD patterns of dried "pure" HA and selenium-enriched (SeHA) powders are shown in Figure S1. Both diffractograms show only the HA reflections (JCPDS \#09-0432). However, the SeHA pattern has broader reflections than "pure HA", which means fine crystallites and lower crystallinity. ${ }^{26,30}$ The average crystallite sizes (in $\mathrm{nm}$ ), as determined using Scherrer's equation along the $a$ and $c$ crystallographic axes, with unit cell parameters is presented in Table S1. The crystallite size of the SeHA sample is significantly smaller than "pure HA" and amounts to $<10 \mathrm{~nm}$.

Particle morphology of the obtained powders was investigated by TEM. The representative TEM image of the SeHA sample is shown in Figure 1. The SeHA material is composed of nano-sized, plate-like, slightly elongated particles with a great tendency to agglomerate.

FT-IR and ${ }^{31} \mathrm{P}$ ssNMR spectroscopies were used to analyze the effect of the selenite substitution on the structure (Figures S2 and S3). The FT-IR spectrum of SeHA confirms a poorly crystalline (nanocrystalline) apatitic structure. The main phosphate bands $\left(1,200-1,900 \mathrm{~cm}^{-1}\right)$ are broader and poorly resolved. ${ }^{31}$

A very weak band at about $3,570 \mathrm{~cm}^{-1}$ can be observed in the spectrum of the SeHA sample, which corresponds

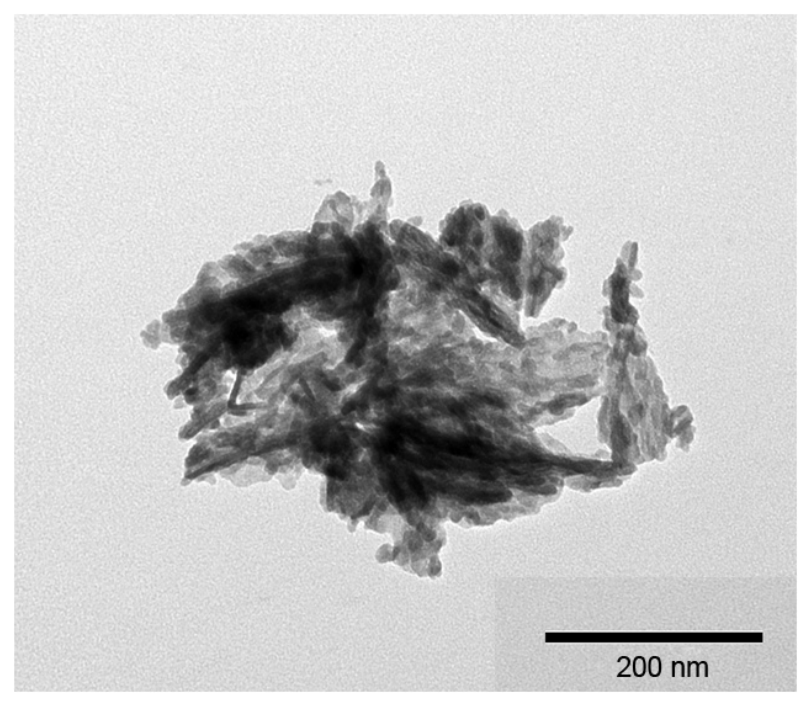

Figure I TEM image of the SeHA powder.

Note: Magnification: 200,000x.

Abbreviations: TEM, transmission electron microscopy; SeHA, selenium-containing hydroxyapatite. to the vibrations of structural $\mathrm{OH}$ groups. The libration bands of $\mathrm{OH}$ groups (at about $630 \mathrm{~cm}^{-1}$ ) are not visible. Relative intensity of the bands derived from water (at about $3,440 \mathrm{~cm}^{-1}$ stretching vibrations, and $1,633 \mathrm{~cm}^{-1}$ bending vibrations) is much larger for the SeHA sample. It is worth remembering that the crystals in SeHA material are very fine and have a strong tendency to form clusters. ${ }^{32}$ Water from the interior of these clusters cannot be removed completely during drying at a moderate temperature $\left(\sim 130^{\circ} \mathrm{C}\right)$.

The bands $1,450-1,418 \mathrm{~cm}^{-1}$ on the spectrum are evidence of trace amounts of carbonate ions, which could be introduced into the structure as impurities. Their number was estimated using the Clasen and Ruyter method as $<0.5 \mathrm{wt} . \% .^{33}$ These were easily detected at $767 \mathrm{~cm}^{-1}$ and were much less intense at $730 \mathrm{~cm}^{-1}$, corresponding to the vibrations of $\mathrm{SeO}_{3}{ }^{2-}$ groups. It can be noticed concurrently that there are no bands derived from other selenium ions on the spectrum. ${ }^{23}$

${ }^{31} \mathrm{P}$ NMR spectra are shown in Figure S3 (in the Supplementary materials). The presence of selenite (IV) ions in SeHA material results in a significant widening of the ${ }^{31} \mathrm{P} N M R$ line at about $3.1 \mathrm{ppm}$, corresponding to phosphorus-31 nuclei in SeHA. This proves a decrease in material crystallinity and at the same time, the development of a hydrated surface layer. ${ }^{34}$ Our recent ${ }^{77}$ Selenium NMR studies showed that $\mathrm{SeO}_{3}{ }^{2-}$ ions in $\mathrm{HA}$ are localized not only within the crystal lattice in the position of $\mathrm{PO}_{4}^{3-}$ ions, but also in the hydrated surface layer. We can assume that the location of these ions will determine their release from the material.

\section{SeHA/ALG microgranules}

The next step was to prepare porous microgranules containing SeHA. For this purpose, we used ALG, which was able to cross-link as a result of the exchange of sodium ions for calcium ions. Figure 2 shows the images of microgranules obtained by the SEM method. The collected microgranules have a spherical shape and their size varies in the range of $1.1-1.5 \mathrm{~mm}$ in diameter. Figure $2 \mathrm{~A}$ presents a number of larger pores, which were formed by the addition of ammonium carbonate. Enlarged image (cross-section) B reveals both the presence of large pores and the smaller ones $(\sim 10 \mu \mathrm{m})$ related to the porous structure of HAALG composite.

Sorption studies demonstrated that the granules' material is microporous. The specific surface area $\mathrm{S}_{\mathrm{BET}}$ was about $83 \pm 5 \mathrm{~m}^{2} / \mathrm{g}$ and total pore volume was $0.21 \mathrm{~cm}^{3} / \mathrm{g}$, including mesopores of $0.15 \mathrm{~cm}^{3} / \mathrm{g}$. The pores with diameter of 20-60 nm dominated in the material. 

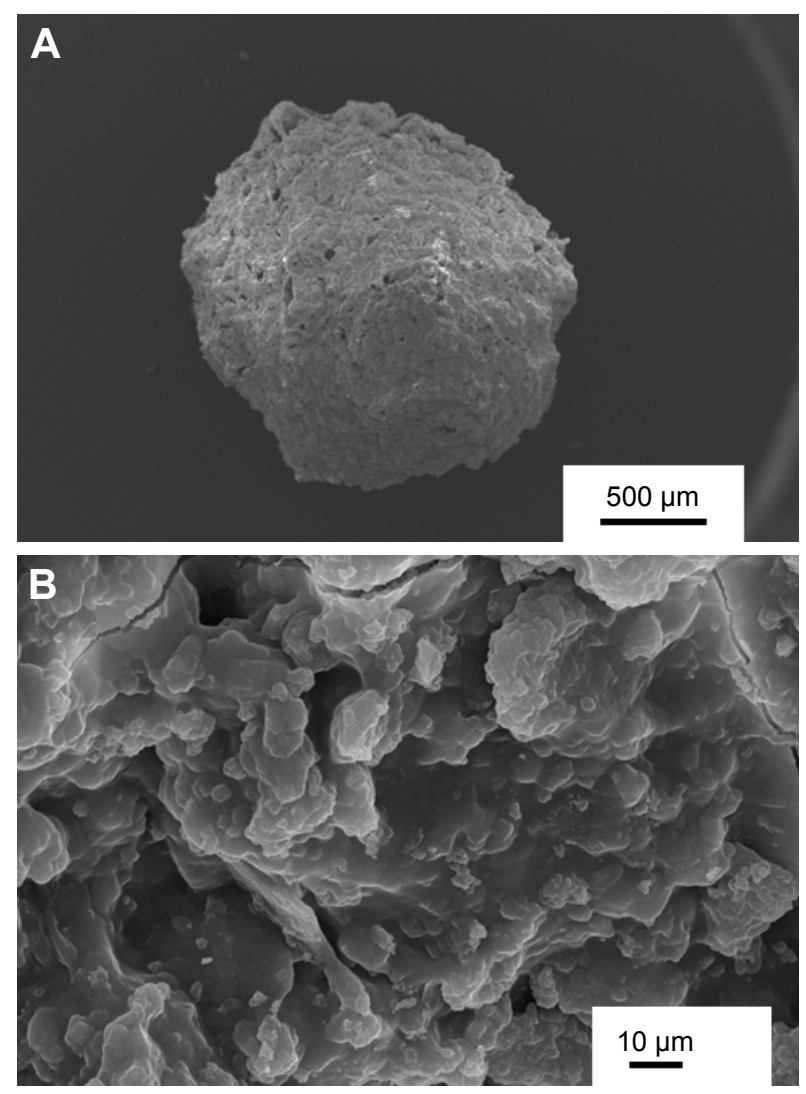

Figure 2 SEM image of the SeHA/ALG microgranule.

Notes: (A) Example of microgranule; magnification: 20×. (B) Cross-section (enlarged view); magnification: I,000X.

Abbreviations: SEM, scanning electron microscopy; SeHA/ALG, seleniumcontaining hydroxyapatite/alginate.

\section{SeHA/ALG microgranules with risedronate sodium}

Two kinds of granules containing RIS were prepared according to the procedure described in the Materials and methods section. The resulting materials were tested using NMR spectroscopy. Figure 3 presents ${ }^{31} \mathrm{P}$ CP NMR spectra for both samples: with RIS introduced into the granules during their formation (SeHA/ALG/RIS I) and soaked in a solution of risedronate (SeHA/ALG/RIS II). In addition, the spectra of "pure" granules, which do not contain risedronate and pure RIS, were made for comparison (Figure 3). The signal at $3.1 \mathrm{ppm}$ characteristic of the nuclei of phosphorus-31 HA dominates in spectra of both types of granules (SeHA; Figure S3) ${ }^{35}$ A quite broad and low-intensity signal at about $15.9 \mathrm{ppm}$ is visible in the spectrum SeHAAlg/RIS I, while in the spectrum SeHA/ALG/RIS II, it is considerably broader and less intense. We can assume that these signals come from the nuclei of RIS phosphorus-31. ${ }^{36,37}$ The spectrum of RIS in this area shows two intense, slightly separated lines at about 17.4 and $19.4 \mathrm{ppm}$ corresponding to the hemipentahydrated

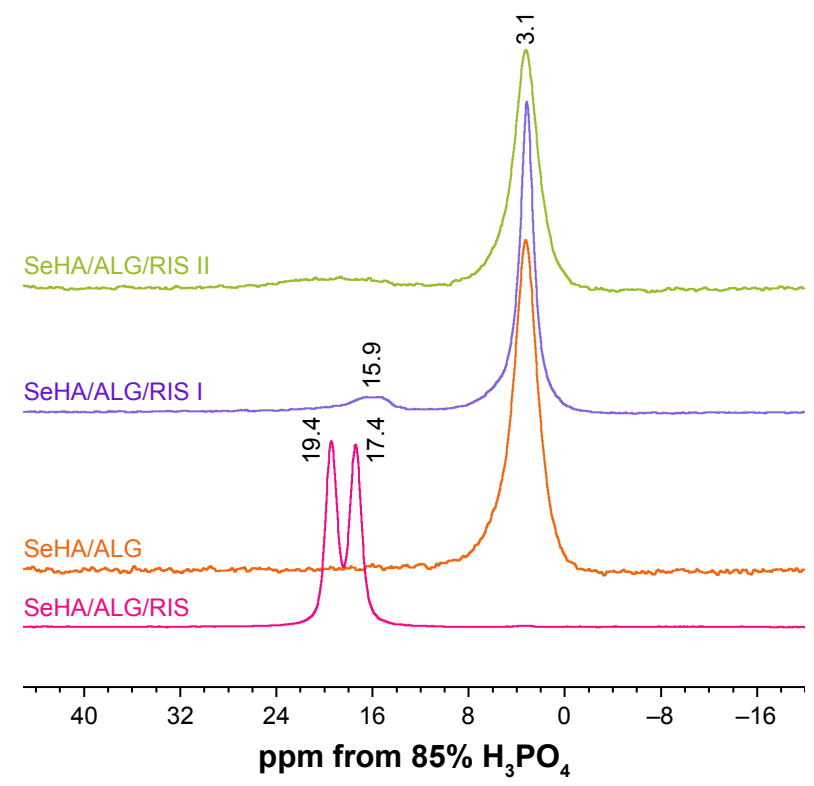

Figure $3{ }^{31} \mathrm{P}$ CP MAS NMR of the obtained materials. $\left(v_{\text {MAS }}=7 \mathrm{kHz}\right)$.

Abbreviations: ALG, alginate; $C P$, cross-polarization; MAS, magic angle spinning; NMR, nuclear magnetic resonance; RIS, risedronate sodium; SeHA, seleniumcontaining hydroxyapatite.

form of RIS. Two resonance lines correspond to the 2 nonidentical phosphonate groups. The presence of the shifted signal in the spectra of both types of granules indicates a change in the chemical surrounding of phosphonate groups as a result of interaction with calcium ions $\mathrm{Ca}^{2+} .36$

${ }^{13} \mathrm{C}$ NMR spectra of the examined granules are presented in Figure 4. Also, the spectra of pure RIS and ALG, from which the granules were obtained, are presented for comparison. Dominant signals from ALG (designated as A)

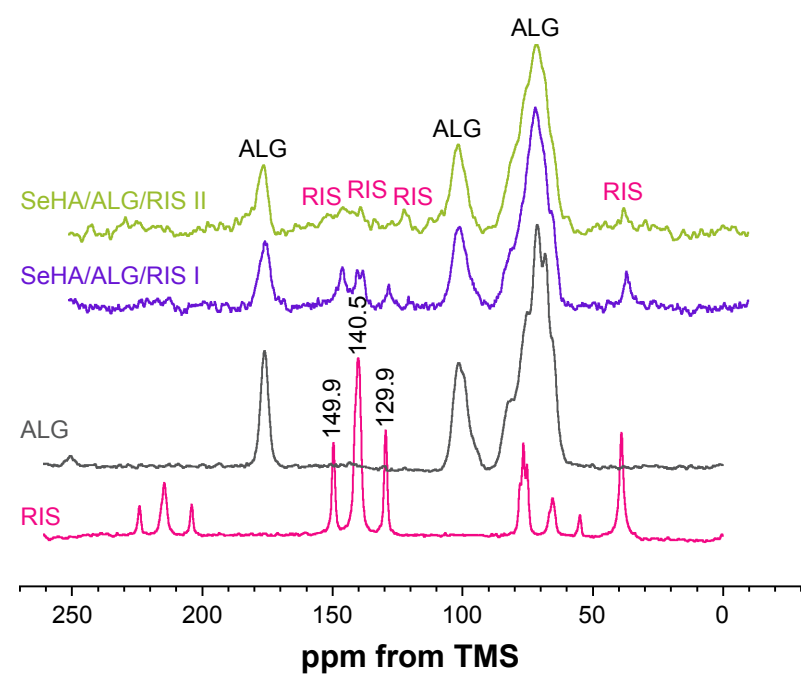

Figure $4{ }^{13} \mathrm{C}$ CP MAS NMR of the obtained materials $\left(v_{\text {MAS }}=7.5 \mathrm{kHz}\right.$ ).

Abbreviations: ALG, alginate; $C P$, cross-polarization; MAS, magic angle spinning; NMR, nuclear magnetic resonance; RIS, risedronate sodium; SeHA, seleniumcontaining hydroxyapatite; TMS, tetramethylosilane. 


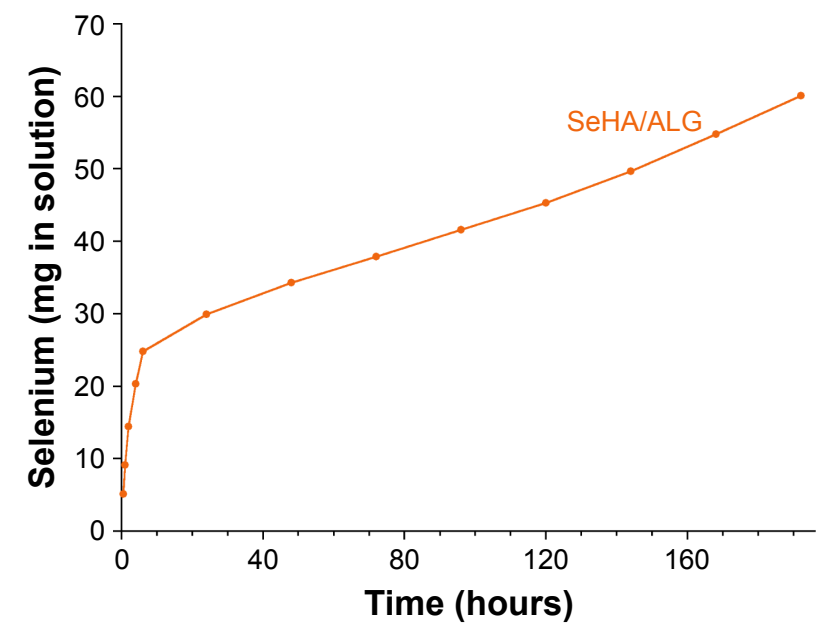

Figure 5 Selenium release profile from the SeHA/ALG microgranules. Abbreviation: SeHA/ALG, selenium-containing hydroxyapatite/alginate.

are present in the spectra of the granules. Additionally, low-intensity signals in the area of 100-120 ppm and below 50 ppm can be noticed, which can be attributed to RIS present in the samples (lines marked as R). ${ }^{36,38}$ By analyzing the mutual intensity of R/A lines in both samples, it can be easily noticed that the RIS share in granules obtained using the first method is higher than in granules obtained using the second method. Slight shifts of signals $R$, as in the spectra ${ }^{31} \mathrm{P} \mathrm{NMR \text {, }}$ demonstrate the interaction of RIS with calcium ions.

\section{Selenium and risedronate release}

Figure 5 shows the release of selenium from composite granules SeHA/ALG to PBS medium with a $\mathrm{pH}$ value of 7.4. It is easy to notice a high "burst release" rate in the first $10 \mathrm{~h}$ of the experiment. After this time, the process of constant release increase up to $200 \mathrm{~h}$ can be observed. During the first stage, there is probably the release of selenite ions located in the hydrated surface layer of the crystals. ${ }^{32,34}$ This is followed by gradual dissolution of $\mathrm{HA}$ crystals and $\mathrm{SeO}_{3}{ }^{2-}$ ion release from the inside of crystals. The dissolution of HA enriched with selenium, although $\mathrm{pH}=7.4$, is significant. This is primarily due to the morphology and size of SeHA crystals - crystals are very small and characterized by a strongly developed surface area.

RIS release from both types of granules is shown in Figure 6. In the case of granules soaked in RIS solution, the release curve is characterized by slight "burst release" within about $10 \mathrm{~min}$. This is probably related to the release of risedronate adsorbed just at the surface of the granules. Then, the release occurs at a lower rate, which corresponds to the transition of RIS adsorbed within the porous structure of microgranules to the PBS solution.

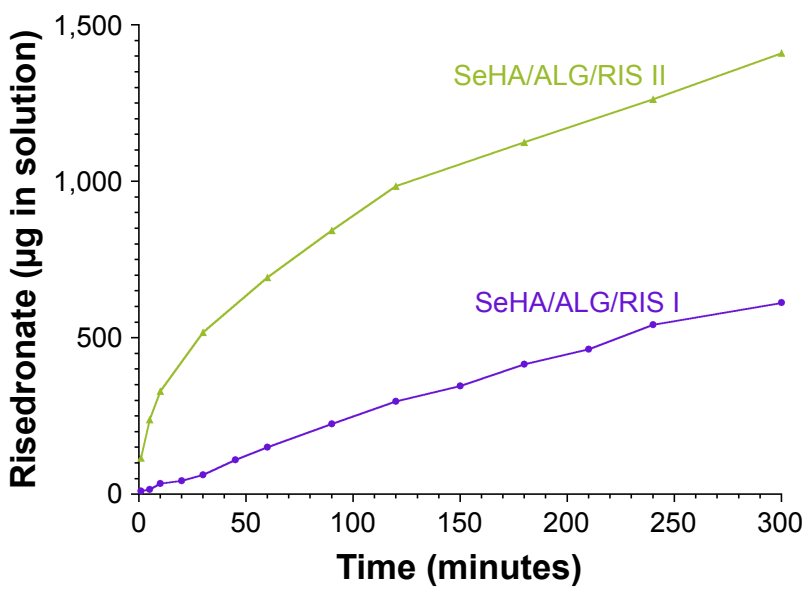

Figure 6 Risedronate release kinetics.

Abbreviations: RIS, risedronate sodium; SeHA/ALG, selenium-containing hydroxyapatite/alginate.

The release curve of RIS for the SeHA/ALG/RIS I sample has a completely different course. It can be said that the relationship of the amount of RIS released over time is linear, and therefore RIS passes into solution at a constant rate. We can therefore say that the way to prepare granules loaded with RIS significantly affects the profile of its release to the $\mathrm{PBS}$ solution at $\mathrm{pH}=7.4$. The introduction of the drug during the preparation of SeHA/ALG/RIS I granules results in its better distribution in microgranules. It should also be noted that much more RIS was released in the process of soaking in RIS solution. However, it is not possible to draw reliable conclusions at this stage. It should only be assumed that the reason may be its higher content in SeHA/ALG/ RIS I granules. The aim of this part of the study was only comparison of RIS release profiles from granules prepared in different ways.

\section{Cytotoxicity against osteosarcoma cells and normal osteoblasts}

MTT cytotoxicity assay revealed that upon $24 \mathrm{~h}$ incubation, composite granules composed of SeHA (SeHA/ALG) and also materials additionally containing RIS (SeHA/ALG/RIS I and II), significantly $(P<0.0001)$ reduced viability of both Saos- 2 and hFOB 1.19 cells by over $90 \%$ compared with the corresponding control cells (Figure 7). No significant differences between cytotoxicity of SeHA/ALG and SeHA/ALG RIS (I and II) extracts were observed, indicating that amount of released selenium from HA was sufficient to provide high antitumor activity of the granules. As a consequence, activity of RIS was masked by high cytotoxic effect of selenium ions. Extract of the control HA/ALG granules showed slight, but statistically significant $(P=0.0076$ for $100 \%$ extract, 


\section{Cytotoxicity against osteosarcoma and normal osteoblast cells}

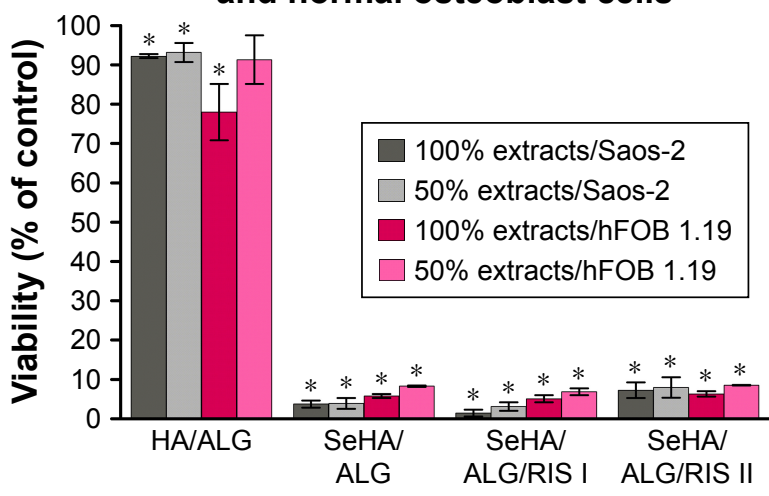

Figure 7 Cytotoxicity evaluation of the granule extracts with the use of MTT test against tumor cells (Saos-2) and normal osteoblasts (hFOB I.19).

Note: *Significantly different results $(P<0.05)$ compared with the negative control of cytotoxicity ( $100 \%$ viability) according to the unpaired $t$-test.

Abbreviations: ALG, alginate; HA, hydroxyapatite; hFOB, human normal osteoblasts; MTT, $2 \mathrm{H}$-tetrazolium bromide; RIS, risedronate sodium; SeHA, seleniumcontaining hydroxyapatite.

$P=0.0295$ for $50 \%$ extract in the case of Saos- 2 cells and $P=0.0001$ for $100 \%$ extract in the case of hFOB 1.19 cells), reduction in cell viability to $78 \%-92 \%$ compared with the negative control of cytotoxicity. However, according to ISO 10993-5, 100\% extract of the implantable material causing reduction in cell viability by $30 \%$ or less should be considered as non-cytotoxic. Thus, extract of control HA/ALG granules was demonstrated to be non-cytotoxic, proving that high cytotoxic effect against the cells was a result of selenium and RIS release from the composite granules. Moreover, according to mentioned standards, the results of the test are considered to be trustworthy if cells exposed to $50 \%$ extracts maintain the same or higher viability as cells exposed to $100 \%$ extracts. ${ }^{29}$ Since viability of Saos-2 and hFOB 1.19 cells exposed to $50 \%$ extracts of granules was slightly higher than viability of the cells exposed to $100 \%$ extracts, it may be concluded that obtained results are reliable.

In this study, extracts of the granules were prepared in accordance with ISO $10993-5$ by $24 \mathrm{~h}$ incubation of the materials in culture medium without preincubation in aqueous solution and without any medium exchange. Thus, high cytotoxic effect of all microgranules against osteosarcoma and normal cells was probably the result of "burst release" of selenium ions during $24 \mathrm{~h}$ extraction time. Accumulated in the extracts, high concentrations of selenium ions caused effective tumor cells' death but it also affected viability of normal osteoblasts. Nevertheless, fabricated in this study, microgranules were designed to be implanted in bone defects just after tumor resection. Taking into account potential biomedical application of produced composite granules, critically high concentration of selenium during the first 24 $\mathrm{h}$ upon implantation would be desired phenomenon since it would provide high antitumor protection. It should be noted that after implantation of the granules in living human body where physiological body fluids constantly flow - just after "burst release" occurring during the first $10 \mathrm{~h}$, the concentration of selenium in the surrounding microenvironment would be probably significantly reduced (due to body fluids flow and Se-release profile occurring at a lower rate, Figure 5). As a consequence, lower and less cytotoxic against normal cells concentration of selenium would be observed at the site of implantation. However, to fully confirm this hypothesis, it is planned to conduct cell culture experiments with the use of extracts prepared applying 2-step procedure, which is not in accordance with ISO 10993-5: 1) preincubation of the materials in culture medium for $24 \mathrm{~h}, 2$ ) medium renewal followed by $24 \mathrm{~h}$ incubation in culture medium to obtain extracts.

\section{Conclusion}

This paper describes the synthesis of SeHA material enriched in selenium ions and method for preparing the new SeHA/ ALG composite containing selenite(IV) ions and RIS. According to physicochemical analysis, the obtained SeHA is nanocrystalline and is characterized by a high specific surface. The content of selenium in the form of selenite(IV) ions in HA was determined at $9.60 \%$ by weight. SeHA material was used to obtain porous microgranules, which were then loaded with RIS in 2 ways. The study analyzed the release of both selenium and the drug. In the first step, selenium is released from the hydrated surface layer of SeHA crystals, and then progressively from the interior of the crystals, which is related to their dissolution in PBS. The release of RIS is dependent on the method of the microgranules' preparation. Moreover, it was demonstrated that fabricated granules release selenium and RIS in amounts sufficient to provide high protection against tumor development at the site of implantation in oncology patients. However, during the first $10 \mathrm{~h}$, when "burst release" of selenium ions is observed, composite microgranules would also reduce viability of normal osteoblasts. Nevertheless, fabricated granules appear to be a very promising implantable material to be used as bone fillers just after tumor resection in patients susceptible to bone tumor relapse.

\section{Acknowledgments}

This work was supported by the research grant (Project NCN DEC-2011/03/D/ST5/05793) of the National Science Center, Poland. Financial assistance was partially provided 
by the Ministry of Science and Higher Education in Poland within the DS2 project of the Medical University of Lublin. The paper was partially developed using the equipment purchased within the agreement No POPW.01.03.00-06010/09-00 Operational Programme Development of Eastern Poland 2007-2013, Priority Axis I, Modern Economy, Operations 1.3. Innovations Promotion.

\section{Disclosure}

The authors report no conflicts of interest in this work.

\section{References}

1. Woodruff MA, Lange $\mathrm{C}$, Reichert J, et al. Bone tissue engineering: from bench to bedside. Mater Today. 2012;15(10):430-435.

2. Drosse I, Volkmer E, Capanna R, de Biase P, Mutschler W, Schieker M. Tissue engineering for bone effect healing: an update on a multicomponent approach. Injury. 2008;39 (Suppl 2):S9-S20.

3. Amini AR, Laurencin CT, Nukuvarapu SP. Bone tissue engineering: recent advances and challenges. Crit Rev Biomed Eng. 2012;40(5): 363-408

4. Fishero BA, Kohli N, Das A, Christophel JJ, Cui Q. Current concepts of bone tissue engineering for craniofacial bone defect repair. Craniomaxillofac Trauma Reconstr. 2015;8(1):23-30.

5. Ramakrishna S, Ramalignan M, Sampath Kumar TS, Soboyejo WO. Biomaterials - a nano approach. Overview of Biomaterials. Boca Raton: CRC Press; 2010.

6. Wang P, Zhao L, Liu J, Weir MD, Zhou X, Xu HH. Bone tissue engineering via nanostructured calcium phosphate biomaterials and stem cells. Bone Res. 2014;2:14017.

7. Iafisco M, Catalucci D. Nano-apatites with designed chemistry and crystallinity for bone regeneration and nanomedical applications. In: Sprio S, Tampieri A, eds. Bio-Inspired Regenerative Medicine. Boca Raton: CRC Press; 2016:47-84.

8. Supova M. Substituted hydroxyapatite for biomedical applications: a review. Ceram Int. 2015;41:9203-9231.

9. Kolmas J, Krukowski S, Laskus A, Jurkitewicz M. Synthetic hydroxyapatite in pharmaceutical applications. Ceram Int. 2016;42(2): 2472-2487.

10. Mourino V, Catallini JP, Roether JA, Dubey P, Roy I, Boccacini AR. Composite polymer-bioceramic scaffolds with drug delivery capability for bone tissue engineering. Expert Opin Drug Deliv. 2013;10(10): 1353-1365.

11. Liao W, Zhang R, Dong C, Yu Z, Ren J. Novel walnut peptide-selenium hybrids with enhanced anticancer synergism: facile synthesis and mechanistic investigation of anticancer activity. Int J Nanomedicine. 2016;11:1305-1321.

12. Tran PA, Sarin L, Hurt RH, Webster TJ. Differential effects of nanoselenium doping on healthy and cancerous osteoblasts in coculture on titanium. Int J Nanomedicine. 2010;5:351-358.

13. Zheng H, Cao JJ, Combs GF. Selenium in bone health: roles in antioxidant protection and cell proliferation. Nutrients. 2013;5(1):97-110.

14. Cai X, Wang C, Yu W, et al. Selenium exposure and cancer risk: and updated meta-analysis and meta-regression. Sci Rep. 2016;6:19213.

15. Bao P, Chen Z, Tai RZ, Shen HM, Martin FL, Zhu YG. Seleniteinduced toxicity in cancer cells is mediated by metabolic generation of endogenous selenium nanoparticles. J Proteom Res. 2015;14(2): 1127-1136.

16. Maiyo F, Singh M. Selenium nanoparticles: potential in cancer gene and drug delivery. Nanomedicine (Lond). 2017;12(9):1075-1089.
17. Rayman MP. Selenium in cancer prevention: a review of the evidence and mechanism of action. Proc Nutr Soc. 2005;64(4):527-542.

18. Lee KY, Mooney DJ. Alginate: properties and biomedical applications. Prog Polym Sci. 2012;37(1):106-126.

19. Dalheim MO, Vanacker J, Najmi MA, Aachmann FL, Strand BL, Christensen BE. Efficient functionalization of alginate biomaterials. Biomaterials. 2016;80:146-156.

20. Augst AD, Kong HJ, Mooney DJ. Alginate hydrogels as biomaterials. Macromol Biosci. 2006;6(8):623-633.

21. Sun J, Tan H. Alginate-based biomaterials for regenerative medicine applications. Materials. 2013;6(4):1285-1309.

22. Russell RG. Bisphosphonates: the first 40 years. Bone. 2011;49(1): 2-19.

23. Drake MT, Clarke BL, Khosla S. Bisphosphonates: mechanism of action and role in clinical use. Mayo Clin Proc. 2008;83(9):1032-1045.

24. Xin ZF, Kim YK, Jung ST. Risedronate inhibits human osteosarcoma cell invasion. J Exp Clin Cancer Res. 2009;28(1):105.

25. Fournier PG, Stresing V, Ebetino FH, Clésardin P. How do bisphosphonates inhibit bone metastasis in vivo? Neoplasia. 2010;12(7): $571-578$.

26. Kolmas J, Oledzka E, Sobczak M, Nałęcz-Jawecki G. Nanocrystalline hydroxyapatite doped with selenium oxyanions: a new material for potential biomedical applications. Mater Sci Eng C. 2014;39:134-142.

27. Cernik RJ. X-ray powder diffractometry. An introduction. Series: chemical analysis, Vol. 138; von Jenkins R, Snyder R. L, eds. New York: John Wiley \& Sons. Angewandte Chemie. 1997;109(12):1417-1418.

28. Kyriakides D, Panderi I. Development and validation of reversedphase ion-pair high-performance liquid chromatographic method for the determination of risedronate in pharmaceutical preparations. Anal Chim Acta. 2007;584(1):153-159.

29. International Organization for Standardization. ISO 10993-5:2009Biological evaluation of medical devices - Part 5: Tests for in vitro cytotoxicity; 2009. Available from: https://www.iso.org/standard/36406. html. Accessed July 21, 2017

30. Thian ES, Konishi T, Kawanobe Y, et al. Zinc-substituted hydroxyapatite: a biomaterial with enhanced bioactivity and antibacterial properties. J Mater Sci Mater Med. 2013;24(2):437-445.

31. Kolmas J, Kalinowski E, Wojtowicz A, Kolodziejski W. Mid-infrared reflectance microscopy of human molars: chemical comparison of the dentin-enamel junction with the adjacent tissues. J Mol Struct. 2010; 966(1-3):113-121.

32. Kolmas J, Groszyk E, Piotrowska U. Nanocrystalline hydroxyapatite enriched in selenite and manganese ions: physicochemical and antibacterial properties. Nanoscale Res Lett. 2015;10(1):989.

33. Clasen Sonju AB, Ruyter IE. Quantitative determination of type A and type $\mathrm{B}$ carbonate in human deciduous and permanent enamel by means of Fourier transform infrared spectrometry. Adv Dent Res. 1997; 11(4):523-527.

34. Kolmas J, Kuras M, Oledzka E, Sobczak M. A solid-state NMR study of selenium substitution into nanocrystalline hydroxyapatite. Int $J \mathrm{Mol}$ Sci. 2015;16(5):11452-11464

35. Sutter B, Taylor RE, Hosner LR, Ming DW. Solid-state 31-phosphorus nuclear magnetic resonance of iron, manganese, and copper-containing hydroxyapatite. Soil Sci Soc Am J. 2002;66(2):455-463.

36. Errassifi F, Sarda S, Barroug A, Legrouri A, Sfihi H, Rey C. Infrared, Raman and NMR investigations of risedronate adsorption on nanocrystalline apatites. J Colloid Interface Sci. 2014;420:101-111.

37. Mukherjee S, Song Y, Oldfield E. NMR investigations of the static and dynamic structures of bisphosphonates on human bone: a molecular model. J Am Chem Soc. 2008;130(4):1264-1273.

38. Pascaud P, Errassifi F, Brouillet F, et al. Adsorption on apatitic calcium phosphates for drug delivery: interactions with bisphosphonates molecules. J Mater Sci Mater Med. 2014;25(10):2373-2381. 


\section{Supplementary materials}

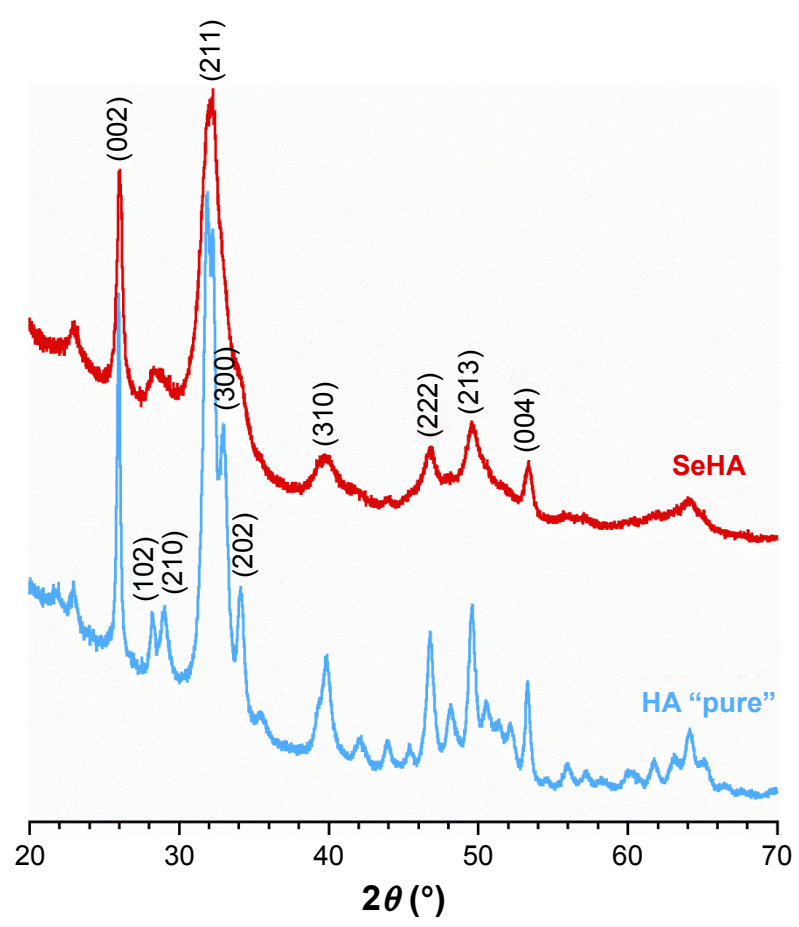

Figure SI PXRD patterns of the SeHA and HA samples.

Abbreviations: HA, hydroxyapatite; PXRD, powder X-ray diffractometry; SeHA, selenium-containing hydroxyapatite.

Table SI The unit cell parameters ( $a$ and $c$ ) and crystallite sizes of the studied samples

\begin{tabular}{|c|c|c|c|c|}
\hline \multirow[t]{2}{*}{ Sample } & \multicolumn{2}{|c|}{$\begin{array}{l}\text { Lattice } \\
\text { parameters }(\AA)^{a}\end{array}$} & \multicolumn{2}{|c|}{ Crystallite size (nm) } \\
\hline & $a$ & c & Along $a$ axis & Along $c$ axis \\
\hline "Pure" HA & 9.4113 & 6.8700 & $25 \pm 3$ & $18 \pm 2$ \\
\hline SeHA & 9.4341 & 6.8596 & $10 \pm 1$ & $8 \pm 2$ \\
\hline
\end{tabular}

Notes: ${ }^{\mathrm{a}}$ The error of the measurements did not exceed $0.3 \%$. Data presented as mean \pm standard deviation.

Abbreviations: HA, hydroxyapatite; SeHA, selenium-containing hydroxyapatite.

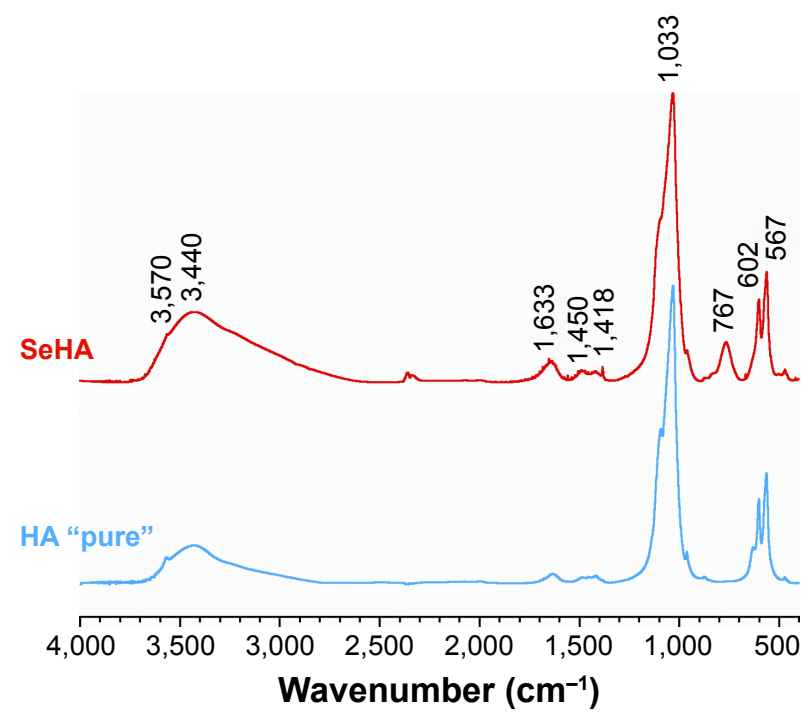

Figure S2 FT-IR spectra of the SeHA and HA samples.

Abbreviations: FT-IR, Fourier transform infrared spectroscopy; HA, hydroxyapatite; SeHA, selenium-containing hydroxyapatite.

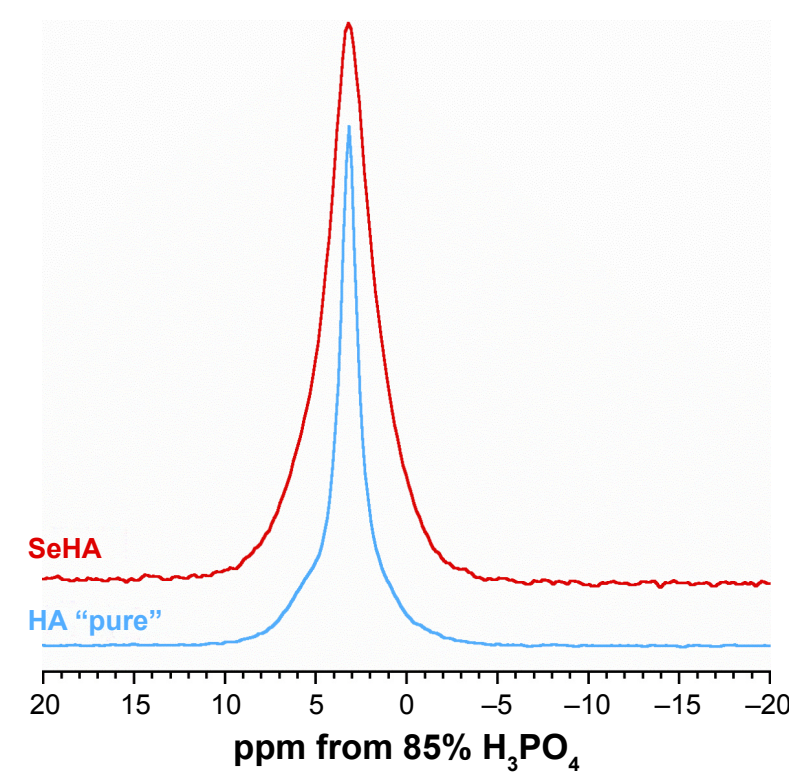

Figure S3 ${ }^{31} \mathrm{P}$ CP MAS NMR spectra of the SeHA and HA samples $\left(v_{\text {MAS }}=7.0 \mathrm{kHz}\right)$. Abbreviations: $\mathrm{CP}$, cross polarization; HA, hydroxyapatite; MAS, magic angle spinning; NMR, nuclear magnetic resonance; SeHA, selenium-containing hydroxyapatite.
International Journal of Nanomedicine

\section{Publish your work in this journal}

The International Journal of Nanomedicine is an international, peerreviewed journal focusing on the application of nanotechnology in diagnostics, therapeutics, and drug delivery systems throughout the biomedical field. This journal is indexed on PubMed Central, MedLine, CAS, SciSearch ${ }^{\circledR}$, Current Contents ${ }^{\circledR} /$ Clinical Medicine,

\section{Dovepress}

Journal Citation Reports/Science Edition, EMBase, Scopus and the Elsevier Bibliographic databases. The manuscript management system is completely online and includes a very quick and fair peer-review system, which is all easy to use. Visit http://www.dovepress.com/ testimonials.php to read real quotes from published authors. 